Received $13^{\text {th }}$ October 2017, Accepted $19^{\text {th }}$ January 2018

Link to $\mathrm{DOI}$ :

10.25220/WNJ/V01.i2.0010

Journal Website:

www.worldnutrijournal.org

\section{Early-menarche as Determinant Factor for Metabolic-risks: An Epidemiology Perspectives among Adolescent Girls Age 13-15 years old in Jakarta-Indonesia}

\author{
Ririn Hariani, ${ }^{1}$ Vikie Nouvrisia, ${ }^{2}$ Dhevinia Yustikarani, ${ }^{2}$ Saptawati Bardosono, ${ }^{2}$ \\ 1. Dharmais Cancer Hospital, Jakarta, Indonesia \\ 2. Department of Nutrition Medical Faculty Universitas Indonesia - Cipto Mangunkusumo General \\ Hospital.
}

\begin{abstract}
Introduction: Early menarche predicts higher body mass index (BMI) and adiposity in adult life, and it has been associated with risk factors of cardiometabolic diseases such as elevated triglycerides and waist circumferences also higher risk of adult diabetes. This study aims to explore early-menarche as determinant factor for metabolic-risks among adolescent girls age 1315 years old.

Methods: This cross-sectional study was undertaken in adolescent girls age 13-15 years old in all five municipalities in Jakarta-Indonesia, from January 2014 to May 2016. Data collected by using standardized measures for dietary intake, nutritional status indicators, physical activity level, blood pressure, blood glucose and lipid profile, and statistically analyzed by independent-t or Mann-Whitney test.

Result: A total of 194 adolescent girls participated in this study. Early menarche was found in $22.68 \%$ of all subjects. There was no association between menarche status and daily macronutrients intake pattern and physical activity level score. There was asscociation between menarche status and nutritional status indicators. Early menarche subjects had significantly body mass index (BMI) $(p<0.001)$, CDC-percentile $(p<0.001)$, WHO Z-score $(p<0.001)$, and waist circumference $(W C)$ values $(p=0.02)$. Furthermore, early menarche subjects also had higher systolic blood pressure $(p=0.035)$, total cholesterol level $(p=0.028)$, LDL-cholesterol level $(p=0.013)$, and triglyceride level $(p=0.026)$. There was no association between menarche status and diastolic blood pressure, fasting blood glucose, HDL-C level, and lipid profile ratio.

Conclusion: Early menarche is an important determinant factor of metabolic risks, and balance between dietary intake and physical activity level should be prioritized among them.
\end{abstract}

Keywords Critical Care Nutrition; early menarche; adolescent girls; metabolic risks; dietary intake, nutritional status indicators

\section{Introduction}

Adolescence is an important period of life because puberty occurred in this phase which marked by changes in the biological, physiological, psychosocial, and cognitive aspects. ${ }^{1,2}$ Physical and developmental changes in adolescent are strongly influenced by nutritional state. Adolescent require

\section{Corresponding author:}

Saptawati Bardosono, MS, PhD

Department of Nutrition Medical Faculty Universitas Indonesia - Cipoto Mangunkusumo General Hospital Email address : tati.bardo@yahoo.co.id 
some of the highest energy and protein than any other age group due to the high velocity of growth. ${ }^{3}$ Nutrition is important at any different stage of life and poor nutrition has a great impact across generations. Adolescent girls will also become a mother who would conceive and give birth. For example, an anemia woman is likely to deliver a low birth weight baby. Otherwise, the complications during pregnancy or delivery will increase when an obese woman is pregnant, such as premature delivery and a low birth weight baby, or if her pregnancy is considered full term, her baby has a great risk to grow into obese child and adolescent. $^{4}$

Adolescent girls are characterized by the spurt in somatic growth, secondary sexual characteristics development, and the first menstrual period which called menarche. ${ }^{5}$ The timing of menarche is affected by many factors such as endogenous hormonal regulations, nutritional status, genetic, environmental conditions, socioeconomic status, and education. Nutrition can influence the production of gonadotropin hormone. The formation of gonadotropin hormone and other hormones is accelerated by good nutrition thus affect the coming of menarche. Several studies reported there was an association between nutritional status with age at menarche. Underweight associated with menarche delay, while obesity associated with early sexual maturation. ${ }^{6,7}$ Age at menarche get a great attention because of its influence on health implications. Early age at menarche has associated with higher body mass index (BMI) and excess body fat in adult life. ${ }^{8}$ Mueller, et $\mathrm{al}^{9}$ have reported that early age at menarche is associated with risk factors of cardiometabolic diseases as elevated triglycerides and waist circumferences also higher risk of adult diabetes. This study aims to explore earlymenarche as determinant factor for metabolic-risks among adolescent girls aged 13-15 years old in Jakarta.

\section{Materials and Methods}

This cross-sectional study was undertaken in adolescent girls aged 13-15 years in all five municipalities in Jakarta-Indonesia, from January 2014 to Mei 2016. This study was part of previous study which was already published. ${ }^{10}$ Subjects were recruited by multistage random sampling from Public and Private Junior High School within the municipalities. Selected schools, which have more than 60 female students were randomised by using online randomization (www.randomizer.org) to get five Public and five Private Junior High Schools. Sampling was done after obtaining permission from the Local National Unity and Politics of Jakarta. There were two selected schools refused to participate and withdrew from the study. Minimal sample size required for this study was 278 girls based on sample size calculation using prevalence of early menarche of $23.6 \%{ }^{6}$ for degree of significance alpha of 5\% and degree of reliability of $5 \%$. This study was approved by the Health Research Ethics Committee Faculty of Medicine Universitas Indonesia Cipto Mangunkusumo Hospital (No.634/H2.F1/ETIK/ 2013).

Medical history, general physical examination, and anthropometric measurement were performed in the subjects. Subjects were interviewed on their socio-demographic characteristics, age of menarche (early menarche status was defined as menarche before 12 years of age), dietary nutrients intake, and physical activity. Interview on dietary nutrients intake at during the past month, including food sources and quantity of energy, carbohydrate, protein, fat, and fiber intake, and also the way to prepare and cook the meals, were done by experienced nutritionist using the semi-quantitative Food Frequency Questionnaire (FFQ) then adjusted by the estimated size of the household which compared with food models. Results were analyzed using Nutrisurvey 2007. While physical activity level was assessed by using the Physical Activity Questionnaire (PAQ), i.e. PAQ-for children (PAQ-C) used to adolescent girls aged 13-14 years and PAQ-for adolescent (PAQ-A) used to adolescent girls aged 15 years.

Blood pressure measurement was performed to get systolic and diastolic blood pressure and nutritional status was evaluated using four indicators: weight $(\mathrm{kg})$ per height $(\mathrm{m})^{2}$ (Body Mass Index; BMI), BMI according to WHO Zscore and CDC-percentile, and waist-circumference (WC). Waist-circumference was measured at the mid point between the last rib and the iliac crest. 
A total of $7 \mathrm{ml}$ of venous whole blood was drawn from the cubital vein by a trained phlebotomist at 7.00 until 10.00 in the morning after subject fasted for 12 hours for examination of fasting blood glucose. Blood sample was kept at room temperature for 30-45 minutes, and centrifuged at $1500 \mathrm{rpm}$ for 15 minutes at $4^{\circ} \mathrm{C}$ to get blood serum and use for examination of total cholesterol level. Data of fasting blood glucose and total cholesterol level were recorded using special forms. The remaining blood serums were kept at $20^{\circ} \mathrm{C}$ at Dharmais Hospital National Cancer Center Laboratory for two years and were used for examining HDL cholesterol and triglyceride level using enzymatic colorimetric method. LDL cholesterol was calculated using the Friedewald equation (LDL cholesterol $=$ total cholesterol HDL cholesterol - (triglyceride/5).

Data were recorded using special forms. Data were edited, coded, and submitted into working sheets in the computer using Statistical Package for the Social Sciences (SPSS) version 20.0. Data were presented into descriptive and analytical approaches. Statistical analyses using unpaired $t$ test or Mann-Whitney test were conducted to determine daily macronutrients intake pattern, nutritional status indicator, physical activity level (PAL), and metabolic profiles based on menarche status.

\section{Results}

Subjects who met the study criteria (had experienced menstruation, without history of chronic disease and therapy on steroids, without physically and mentally disability, and subjects' parents provided written informed consent) were 230 girls. However, only 194 adolescent girls had completed the measurements, representing the eight junior high schools across Jakarta. Most girls came from a low-income family and characteristics of all subjects were summarized in Table 1. Subjects were stratified into two different group based on the menarche status (Table 2). Early menarche was found in $22.68 \%$ of all subjects. All nutritional status indicators (BMI $p<0.001$, CDC-percentile $p<0.001$, WHO Z-score $p<0.001$, WC $p=0.02$ ) were associated with menarche status.
Table 1 Subjects' Socio-demographic characteristics $(n=194)$

\begin{tabular}{lc}
\hline Variables & $\mathrm{n}(\%)$ \\
\hline Age, years & $101(52.1)$ \\
13 & $82(42.3)$ \\
14 & $11(5.7)$ \\
15 & \\
Father & $75(38.7)$ \\
$\quad$ Education status & $119(61.3)$ \\
$\quad$ Up to Junior High School & \\
$\quad$ Senior High School and & \\
over & \\
Job status & $69(35.5)$ \\
$\quad$ Permanent job & $125(64.5)$ \\
$\quad$ Non-permanent job & \\
Mother & \\
Education status & $90(46.4)$ \\
$\quad$ Up to Junior High School & $104(53.6)$ \\
$\quad$ Senior High School and & \\
over & \\
Job status & $19(9.8)$ \\
$\quad$ Permanent job & $20(10.4)$ \\
$\quad$ Non-permanent job & $155(79.8)$ \\
$\quad$ Not working & \\
Family income, per month & $162(83.5)$ \\
Up to IDR 3,000,000 & $32(16.5)$ \\
More than IDR 3,000,000 & \\
\hline IDR, Indonesia currency in rupiahs $(1 U S \$ 13,000$ IDR $)$ \\
\end{tabular}

High BMI, CDC-percentile, WHO Z-score, and WC were found in subjects with early menarche. There was no association between menarche status and daily macronutrients intake pattern and physical activity level score.

Regarding to the metabolic risks, in this study, menarche status was associated with systolic blood pressure $(p=0.035)$, total cholesterol level $(p=0.028)$, LDL-cholesterol level $(p=0.013)$, triglyceride level $(p=0.026)$. However, there was no association between menarche status and diastolic blood pressure, fasting blood glucose, HDL-C level, lipid profile ratio. 
Table 2 Subjects' metabolic profiles based on early menarche status

\begin{tabular}{|c|c|c|c|c|}
\hline Variables & $\begin{array}{c}\text { All } \\
(\mathrm{n}=194)\end{array}$ & $\begin{array}{l}\text { Early Menarche } \\
\qquad(\mathrm{n}=44)\end{array}$ & $\begin{array}{l}\text { Non-Early Menarche } \\
\qquad(\mathrm{n}=150)\end{array}$ & $p$-value \\
\hline \multicolumn{5}{|l|}{$\begin{array}{l}\text { Daily macronutrients intake } \\
\text { pattern }\end{array}$} \\
\hline Energy, kcal & $1584(703-2963)^{\dagger}$ & $1689 \pm 519^{*}$ & $1579(703-2963)^{\dagger}$ & $0.415^{\pi}$ \\
\hline Carbohydrate, $g$ & $213.1(74.3-432.9)^{\dagger}$ & $228.8 \pm 74.4^{\ddagger}$ & $213.3(74.3-432.9)^{\dagger}$ & $0.833^{\pi}$ \\
\hline Fats, $g$ & $55.8(14-121)^{\dagger}$ & $58(14-121)^{\dagger}$ & $57.6 \pm 19.7^{\star}$ & $0.342^{\pi}$ \\
\hline Protein, $g$ & $46.4\left(13.8-229.0^{\dagger}\right.$ & $48.8(21.1-110.1)^{\dagger}$ & $46.2(13.8-229.0)^{\dagger}$ & $0.863^{\pi}$ \\
\hline Fiber, $g$ & $5.7(0.8-20.4)^{\dagger}$ & $5.1(1.5-20.4)^{\dagger}$ & $6.0(0.8-19.6)^{\dagger}$ & $0.598^{\natural}$ \\
\hline \multicolumn{5}{|l|}{ Nutritional status indicator } \\
\hline BMI, $\mathrm{kg} / \mathrm{m}^{2}$ & $20.0(13.0-32.6)^{\dagger}$ & $22.2 \pm 3.8^{\ddagger}$ & $19.3(13.0-32.2)^{\dagger}$ & $<0.001$ ब \\
\hline CDC-percentile & $59.2(0-98.6)^{\dagger}$ & $74.9(1.6-98.6)^{\dagger}$ & $51.1(0-98.0)^{\dagger}$ & $<0.001^{\text {ब }}$ \\
\hline WHO z-score & $0.1 \pm 1.1^{\ddagger}$ & $0.7 \pm 1.0^{\ddagger}$ & $0 \pm 1.1^{\ddagger}$ & $<0.001^{\S}$ \\
\hline Waist-circumference, $\mathrm{cm}$ & $64.5(50.5-88.0)^{\dagger}$ & $67.0(55.0-88.0)^{\dagger}$ & $63.0(50.5-88.0)^{\dagger}$ & $0.02^{\pi}$ \\
\hline Physical activity level score & $1.9 \pm 0.3^{\ddagger}$ & $1.9 \pm 0.4^{\ddagger}$ & $1.8 \pm 0.3^{\ddagger}$ & $0.215^{\S}$ \\
\hline \multicolumn{5}{|l|}{ Blood pressure, mmHg } \\
\hline Systolic & $110(80-140)^{\dagger}$ & $110(84-122)^{\dagger}$ & $110(80-140)^{\dagger}$ & $0.035^{\pi}$ \\
\hline Diastolic & $70(58-90)^{\dagger}$ & $70(60-84)^{\dagger}$ & $70(58-90)^{\dagger}$ & $0.805^{\natural}$ \\
\hline Fasting blood glucose, $\mathrm{mg} / \mathrm{dL}$ & $83(55-163)^{\dagger}$ & $82.5(57.0-163.0)^{\dagger}$ & $82.3 \pm 11.6^{\ddagger}$ & $0.912^{\pi}$ \\
\hline \multicolumn{5}{|l|}{ Lipid profiles, mg/dL } \\
\hline Total-C & $170.7 \pm 25.7^{\ddagger}$ & $178.2 \pm 24.2^{\ddagger}$ & $168.5 \pm 25.8^{\ddagger}$ & $0.028^{\S}$ \\
\hline LDL-C & $102.7 \pm 25.6^{\ddagger}$ & $111.1 \pm 23.6^{\ddagger}$ & $100.2 \pm 25.8^{\ddagger}$ & $0.013^{\S}$ \\
\hline HDL-C & $49.3 \pm 10.0^{*}$ & $50.0 \pm 8.9^{*}$ & $49.1 \pm 10.3^{\ddagger}$ & $0.632^{\S}$ \\
\hline Triglycerides & $85(34-248)^{\dagger}$ & $72(39-240)^{\dagger}$ & $88(34-248)^{\dagger}$ & $0.026^{\pi}$ \\
\hline \multicolumn{5}{|l|}{ Lipid profile ratio } \\
\hline Total-C:HDL & $3.39(1.74-11.29)^{\dagger}$ & $3.58(2.34-7.10)^{\dagger}$ & $3.36(1.74-11.29)^{\dagger}$ & $0.248^{\pi}$ \\
\hline Triglyceride:HDL & $1.73(0.54-8.00)^{\dagger}$ & $1.52(0.66-5.22)^{\dagger}$ & $1.89(0.54-8.00)^{\dagger}$ & $0.070^{9}$ \\
\hline LDL:HDL & $2.03(0.61-8.92)^{\dagger}$ & $2.22(1.21-5.44)^{\dagger}$ & $1.99(0.61-8.92)^{\dagger}$ & $0.075^{\natural}$ \\
\hline
\end{tabular}

All: all subjects; early menarche: subjects with early menarche status which defined as menarche before 12 years of age ; non-early menarche: subjects with non-early menarche status which defined as menarche 12 or over 12 years of age; C: cholesterol.

${ }^{\dagger}$ median (minimum-maximum), ${ }^{\ddagger}$ mean \pm SD; ${ }^{\S}$ unpaired $t$ test; ${ }^{\circledR}$ Mann-Whitney U test. 


\section{Discussion}

To our knowledge, this study was the first research conducted in Indonesian adolescents girls that assess metabolic risks in early menarche accompanied by other factors such as daily macronutrients intake pattern, nutritional status indicators, and physical activity level. The advantages of this research include that it could be generalized to the population of adolescent girls aged 13-15 especially in low-income urban area representing the eight junior high schools among all municipalities in Jakarta, and the random selection. Blood sample collection was also carried out at the same time, i.e. in the morning after subjects fasted to prevent influence of dietary intake to metabolic profile. Subjects were also carried out on fairly strict inclusion criteria to minimize other variations of health conditions that could affect the subjects. Meanwhile, the weakness of this study as it used cross-sectional design that could be threatening by the possibility of the recall bias when taking dietary intake and physical activity data.

In our study, early menarche was found in $22.68 \%$ of all subjects. Similar result was reported in other study. A study in 161 students of junior high school in Semarang reported 23.6\% subjects experienced early menarche. ${ }^{11}$ The age at menarche has decreased steadily worldwide in recent decades. Study in South Korea found the declining trend in the average age at menarche 0.68 years per decade. $^{12}$ Cross-sectional and longitudinal data general population of the United States reported that there was a declining average age at menarche approximately 14.8 years in the late 1800 's to 13 years by 1950 . The average age at menarche has declined over time probably as a result of improvements in nutrition and overall health. ${ }^{13}$

It has been shown that childhood overweight are related to earlier menarche and that earlier menarche is associated with higher body mass index (BMI) in later life. ${ }^{8}$ In this study, subjects with early menarche had higher nutritional status indicators such as BMI, BMI CDC-percentile, BMI WHO Z-score, and waist circumference (WC) than non-early menarche subjects. Our results are consistent with other studies showing associations of early menarche status with nutritional status indicators. A cohort study over a 25 years of follow-up in 2,583 women (AfricanAmerican $=1,333$; White $=1,250$ ) aged $18-30$ years at baseline from the Coronary Artery Risk Development in Young Adults (CARDIA) study showed that earlier menarche was associated with grater BMI and WC for both African-American and White women. ${ }^{14}$ Mueller et al. ${ }^{9}$ reported there was association between early menarche and higher WC and BMI in 8,075 women aged 35-74 years in the Brazilian Longitudinal Study of Adult Health. Earlier menarche ( $<11$ years vs. 13-14 years) was significantly associated with higher WC and BMI. Study in 12,336 women who participated in the Korean National Health and Nutrition Examination Survey 2010 to 2013 reported that women with early menarche were more likely to exhibit a higher BMI and WC relative to the other groups. ${ }^{15}$ The association between onset of menarche and waist circumference may be attributable to the physiological changes of hormones and body composition as the effect of gain of fat mass, the hormonal status and normal physiological changes in body composition during puberty in adolescent girls. ${ }^{16}$

Nutritional status becomes an important factor in menarche. Adolescent girls with undernutrition would experience delay in menarche compared to adolescent girls with normal nutritional status. Delay in menarche is due to a low intake of calories, carbohydrate, fat, protein, and other nutrients, which then affect production of hormone. ${ }^{6}$ Several study showed that early menarche mostly was associated with low fiber intake $^{17-19}$ and high animal protein. ${ }^{18-21}$ In this study, there was no differences in daily macronutrients intake pattern between two groups. A prospective study in 213 girls follow-up to 4 years showed that there was no association between energy intake (carbohydrate, fat, and protein) and early menarche. ${ }^{22}$ It might be explained to the fact that nutrient intake does not directly affect menarche status. Macronutrients intake in our study was obtained from interviewed that based on subject's memory on that time and may describe short term intake. Menarche status is more related to excess body fat in which describes a longterm condition of imbalance energy as a result of high energy intake and could be assessed by 
anthropometric measurements using nutritional status indicators. Most of subjects had low energy intake based on Indonesian Recommended Dietary Allowances (RDA). Energy intake lower than energy adequacy could be caused by many factors. RDA is used for planning basic food consumption of people in particular region to achieve optimal nutrition and health status. RDA is not intended to assess level of individual nutrient intake. Individual energy adequacy should be based on age, sex, weight, height, physycal activity level, thermic effect of food, and growth factors specifically for children and adolescents. ${ }^{23}$ In this study, the largest macronutrient contribution to total energy intake was derived from fat. This could be caused by various factors such as economic factors, food availability, and diet pattern. Family income under regional minimum wage could affect the fulfillment of quality and quantity nutritional intake. They chose type of food with high dense-energy especially high fat diet which more affordable than balance diet. Most of the parents have low education level which could influence diet pattern in the family. ${ }^{10}$

Several study showed that physical activity level associated with menarche status. Dreyfus et al. ${ }^{14}$ reported that early menarche was associated with lower physical activity level for both AfricanAmerican and White women. In this study, there was no difference in physical activity level score between two groups in our study. It might due to the fact that most of girls has low physical activity level. Physical activity tends to decrease with age, especially after a child becomes adolescent, which often occurs in adolescent girls. In childhood, physical activity and exercise is a positive activity and fun activity, but as age increases, that perception has changed. Research shows that the decrease in physical activity tends to occur at the age of 13 to 18 years. $^{24}$

The timing of menarche has been reported to affect metabolic and cardiovascular health in adolescence. ${ }^{25}$ Several studies reported association between early menarche and increased risk for cardiovascular disease such as type 2 diabetes, metabolic syndrome, and high blood pressure. ${ }^{14}$ Early age at menarche has been associated with increased blood pressure in many studies. In this study, menarche status was associated with systolic blood pressure, but not with diastolic blood pressure. Women with earlier menarche were more likely to have reported hypertension at recruitment than those with later menarche, according to a UK population-based cohort study, The Million Women Study. This study recruited 1.3 million women 50 to 64 years of age who had been invited for routine breast cancer screening by the National Health Service (NHS) screening programs of England and Scotland between 1996 and 2001. They reported an increased risk of hospitalization or death from hypertensive disease in women with early menarche. ${ }^{25}$ Similar result of our study was found in a population-representative birth cohort, "Children of 1997", in Hong Kong which assessed the association of maternal age of menarche with blood pressure. Earlier maternal age of menarche was associated with higher systolic blood pressure in adolescence. Maternal age of menarche was not associated with diastolic blood pressure. The association of maternal age of menarche with systolic blood pressure possibly partially driven by the association of earlier maternal age of menarche with greater excess of body fat and/or with earlier pubertal timing. ${ }^{26}$

Early menarche is strongly associated with obesity, which increases the risk of cardiometabolic disease. It might be because obesity and puberty may influence each other through a hormonal changes and insulin resistance. ${ }^{14}$ In this study, menarche status did not related to fasting blood glucose level. In contrast, a cross-sectional study of 2,039 premenopausal and postmenopausal women aged 44 to 56 years in Korea demonstrate a significant association between earlier age at menarche and increased risk of dysglycemia even at the pre-diabetes level. ${ }^{27}$ There was no association between fasting blood glucose and age at menarche in this study. This shows that insulin resistance not always characterized by elevated glucose level.

Overweight or obesity in adolescent, particularly accumulation of fat in abdominal would increase waist circumference which related to increases risk of dyslipidemia, hypertension, insulin resistant or hyperinsulinemia, and impaired glucose tolerance or type 2 diabetes, which led to metabolic syndrome. ${ }^{28}$ The metabolic syndrome is likely to increase in developing countries due to changes in diet and lifestyle. The increased consumption of 
high-calorie diet and fast food containing high amount of carbohydrate and fat, along with the increasing sedentary lifestyle shows the major factors that can increase prevalence of overweight in adolescent. ${ }^{29}$ It was found that adolescent girls with early menarche have higher BMI and waist circumference than adolescent with normal onset of menarche in our study. Early menarche related to amount of adipose tissue, which could be assessed by antropometric measurement such as waist circumference and BMI. Excess of fat is influenced by imbalance of energy intake and physical activity level. As we know, excess of fat was reported as one of risk factor that led to metabolic disease due to its association with metabolic risk factors. Therefore, it can be concluded that early menarche is an important determinant factor of metabolic risks. Adolescents with early menarche already have several metabolic risks that will become to any metabolik disease in later life. Nutrition is a crucial matter in adolescent period. It is important to provide adolescent an adequate intake of nutritious food which met their nutritional needs and encourage them to be more active.

\section{Acknowledgements}

The authors thank all the subjects for participating in the study thoroughly. This study received funding from the Research and Public Services Council (DRPM) Universitas Indonesia.

\section{Conflict of Interest}

The authors of this paper declare there is no conflict of interest regarding this research.

\section{Open Access}

This article is distributed under the terms of the Creative Commons Attribution 4.0 International License (http://creativecommons.org/licenses/by/4.0/), which permits unrestricted use, distribution, and reproduction in any medium, provided you give appropriate credit to the original author(s) and the source, provide a link to the Creative Commons license, and indicate if changes were made.

\section{References}

1. Batubara JRL. Adolescent development (Perkembangan remaja. Sari Pediatri 2010;12:21-9.

2. Karapanou O, Papadimitriou A. Determinant of Menarch. Reproductive Biology and Endocrinology 2010;8:115.

3. Children, t. (Save) . Adolescent Nutrition Policy and Programming in SUN+ Countries. London: NXP Europe Ltd; 2015.

4. Branca F, Piwoz E, Schultink W, Sullivan LM. Nutrition and health in women, children, and adolescent girls. BMJ 2015;351:27.

5. Mounir GM, El-Sayed NA, Mahdy NH, Khamis SE. Nutritional Factors Affecting the Menarcheal State of Adolescent School Girls in Alexandria. J Egypt Public Health Assoc 2007;82(3\&4):239.

6. Juliyatmi RH, Handayani L. Nutritional Status and Age at Menarche on Female Students of Junior High School. International Journal of Evaluation and Research in Education 2015;4(2):71.

7. Stang J. Adolescent nutrition. In: Brown JE, editor. Nutrition through life cycle 4th ed. Belmont: Wadsworth; 2011.

8. Schnabel RB. Is It All Determined at Menarche. Circulation 2015;131:227-9.

9. Mueller NT, Duncan BB, Barreto SM, Chor D, Bessel M Aquino EML, , Pereira MA, et al. Earlier age at menarche is associated with higher diabetes risk and cardiometabolic disease risk factors in Brazilian adults: Brazilian Longitudinal Study of Adult Health (ELSA-Brasil. Cardiovascular Diabetology 2014;13(22):1.

10. Hariani R, Bardosono S, Djuwita R, Sutandyo N, Kumala M, Sungkar A, et al. Diet and estradiol level in adolescent girls. Paediatrica Indonesiana. 2016:56(3):134-8.

11. Susanti AV S. Faktor risiko kejadian menarche dini pada remaja di SMPN 30 Semarang. J Nutr College 2012;1:386-407. 
12. Cho GJ, Park HT, Shin JH, Hur JY, Kim YT, Kim SH, et al. Age at menarche in Korean population: Secular trends and influencing factors. Eur J Pediatr 2010;169:89-94.

13. Dreyfus J. Early Pubertal Development and Cardiometabolic Risk: a Life Course Approach. (dissertation). Minnesota: The University of Minnesota, 2013.

14. Dreyfus J, Jacobs DR, Mueller N, Schreiner PJ, Moran A, Carnethon MR, et al. Age at menarche and cardiometabolic risk in adulthood: the Coronary Artery Risk Development in Young Adults Study. J Pediatr 2015;167(2):344.

15. Won JC, Hong JW, Noh JH, Kim DJ. Association Between Age at Menarche and Risk Factors for Cardiovascular Diseases in Korean Women. The 2010 to 2013 Korea National Health and Nutrition Examination Survey. Medicine 2016;95(18):1-7.

16. Chan NPT, Choi KC, Nelson EAS, Chan JC, Kong APS. Associations of pubertal stage and body mass index with cardiometabolic risk in Hong Kong Chinese children: A cross-sectional study. BMC Pediatrics 2015;15:136.

17. Ridder, C.M. De, Thisjssen JHH, Veer PV, Duuren RV, Brunning PF, Zonderland ML, et al. Dietary habits, sexual maturation, and plasma hormones in pubertal girls: a longitudinal study. Am J Clin Nutr 1991;54:805-13.

18. Moisan J, Meyer F, Gingras S. Diet and age at menarche. Cancer Causes Control 1991;1:149-154.

19. Schimdt TJ, Litwack G. Biochemistry of Hormones. In: Textbook of Biochemistry with Clinical Correlation. $6^{\text {th }}$ ed. Canada:Wiley-Liss $\quad$ Publication. 2006. p.892-942.

20. Wen X, Li D, Tozer AJ, Docherty SM, Iles RK. Estradiol, progesterone, testosterone profiles in human follicular fluid cultured granulose cells from luteinized pre- ovulatory follicles. Reprod Biol Endocrinol 2010;8:117-26.

21. Simpson ER. Sources of estrogen and their importance. J Steroid Biochem Mol Biol 2003;86:225-30.

22. Maclure M, Travis LB, Willet W, MacMahon B. A prospective cohort study of nutrient intake and age at menarche. Am J Clin Nutr 1991;54:649-56.

23. Hardinsyah, Riyadi H, Napitupulu V. Kecukupan Energi, Protein, Lemak dan Karbohidrat. Departemen Gizi Masyarakat FEMA IPB dan Departemen Gizi FKUI. 2012.

24. Aznar-Lain S, Webster T, Chicharro JL. Physical Activity and Health in Children and Adolescents. 2006. http://www.msssi.gob.es/en/ciudadanos/prot eccionSalud/adultos/actiFisica/docs/activida dFisicaSaludIngles.pdf. (accessed July $18^{\text {th }}$ 2016).

25. Canoy D, Beral V, Balkwill A, Wright FL. Kroll ME, Reeves GK, Green J, Cairns BJ. Age at Menarche and Risks of Coronary Heart and Other Vascular Diseases in a Large UK Cohort. Circulation 2014;131:237-44.

26. Lai TC, Leung GM, Schooling CM. Maternal Age of Menarche and Blood Pressure in Adolescence: Evidence from Hong Kong's "Children of 1997" Birth Cohort. PLoS ONE 11(7):1-10.

27. Baek TH, Lim NK, Kim MJ, Lee J, Ryu S, Chang Y, et al. Age at menarche and its association with dysglycemia in Korean middle-aged women. Menopause 2015;22(5):542-8.

28. Rodriguez G, Moreno LA, Blay MG, Blay VA, Garagorri JM, Sarria A, et al. Body composition in adolescents: measurements and metabolic aspects. Intenational Journal of Obesity 2004;28.

29. Ventura AK, Loken E, Birch LL. Risk Profiles for Metabolic Syndrome in a Nonclinical Sample of adolescent Girls. Pediatrics
2006;118(6):24 